\title{
Filme Senhora Aparecida: a relação entre o moderno e o tradicional no cinema documental português
}

Leandro Becceneri ${ }^{1}$

Para citar esta resenha:

BECCENERI, LEANDRO; “ Filme Senhora Aparecida: a relação entre o moderno e o tradicional no cinema documental português" In: Revista Intratextos, 2014, vol 6, no1, p. 119125 DOI: http://dx.doi.org/10.12957/intratextos.2014.12722

Recebido em: Setembro, 2014

Aceito em: Junho, 2015

\section{Introdução}

O gênero cinematográfico chamado de documentário utiliza-se da realidade ou fragmentos do real, para construir um discurso audiovisual característico desta prática, com captação de som direto, entrevistas e planos de sequência longos (SALLES, 2005). Neste sentido, Catarina Alves Costa, em Senhora Aparecida, mostra o conflito em um vilarejo português onde os residentes católicos pretendem manter uma tradição local enquanto um jovem padre que assume a paróquia decide implantar novas regras. O filme passa-se no vilarejo de Aparecida que se localiza no chamado Vale do Ave, uma zona Industrial no interior

\footnotetext{
${ }^{1}$ Mestre em Ciências Sociais pela Universidade Federal de São Paulo (UNIFESP), com bolsa de estudos CAPES - Coordenação de Aperfeiçoamento de Pessoal de Nível Superior. Email: leandrobecc @ hotmail.com 
de Portugual. Nesse lugar se realizam todos os anos as comemorações à Senhora Aparecida, que é marcada por uma festa grandiosa e também por uma procissão como pagamento das graças obtidas em promessas feitas à Santa. Essa procissão ocorre com os fieis deitados em caixões simulando um cortejo fúnebre que corta a cidade. $\mathrm{O}$ filme relata os acontecimentos que se seguiram à proibição feita pelo jovem padre da realização desta procissão.

Deste modo, o objetivo da análise é compreender como se dá o desenvolvimento da história do filme, sua temática e seus acontecimentos para assim explicitar a relação entre tradição e modernidade e como esta é construída e retratada pela cineasta em suas várias contradições. O filme não possui um narrador, sendo sua narração feita a partir das falas e das cenas, onde as cenas são dispostas de modo que o espectador consiga compreender o que está se passando apenas através das falas e das situações exibidas.

\section{O filme}

Basicamente, um filme documentário deve selecionar as circunstâncias, as palavras, as situações mais significativas, de forma a evidenciar os elementos simbólicos para construir uma nova realidade dando a ilusão e a compreensão da realidade filmada. Quando se deixa de usar a câmara para documentar a vida social e se passa a usá-la como meio de expressão para examinar detalhadamente a vida social, o processo de filmar pode representar o evento observado (VANOYE, GOLIOT-LÉTÉ, 1994). Senhora Aparecida é um filme de observação, limitando-se ao que ocorre natural e espontaneamente em frente à câmara: este método baseia-se na disposição das pessoas para falarem de si, da sociedade, do passado e do presente. No filme, as questões surgem de forma progressiva e as descobertas associam-se intimamente com o processo de gravação de som e imagem.

Dessa forma, a cineasta consegue quebrar a barreira do distanciamento, sem perder a qualidade do documentário. Este parece ser um meio empregado por ela para conseguir maior veracidade diante dos espectadores, pois a presença incomoda da câmera é amenizada pela relação estabelecida entre câmeras e entrevistados, quando ambos interagem. Quando a equipe toma o depoimento das pessoas a relação entre eles se humaniza, indo além do simples utilitarismo. Cabe destacar a afirmação de MacDougall (1997) que diz que um filme nunca é um feito exclusivo de quem o realizou, sendo também uma realização de quem está sendo retratado. Essa afirmação é relevante no caso do documentário uma vez que há de se considerar até que ponto o coditiano dos indivíduos não é alterado pela presença da câmera nos ambientes. Também é importante ressaltar que o filme se justifica uma vez que será feito 
um registro do momento de conflito a respeito da continuidade de um rito da procissão dos enterros, que acabaria por desaparecer pela proibição do novo padre e que o filme possivelmente será o último registo.

O filme começa mostrando os preparativos para uma procissão católica, em um vilarejo aparentemente rural, no interior de Portugal. Sucessivas cenas vão se passando a fim de mostrar como a festa é organizada, as pessoas envolvidas e seus afazeres. No início é um pouco complicado ao espectador compreender o contexto e as características da festa e seu principal ponto retratado no documentário: uma procissão, dentro da própria festa, onde pessoas - vivas - desfilam pelas ruas dentro de caixões para pagar promessas feitas a santa Senhora Aparecida. Desde a construção de um monumento gigantesco, que os homens carregarão durante a procissão, até o recolhimento de flores e alimentos para a festa, tudo é mostrado no mesmo formato, com a câmera acompanhando de perto as discussões, situações e o convívio entre os moradores. É interessante notar a presença majoritária de idosos organizando os preparativos e trabalhando nas várias funções da festa, o que denota seu aspecto tradicional.

Ao longo do filme, outro ponto ressaltado é quando uma senhora, acompanhada de seu marido, entra em uma longa discussão com o novo padre da comunidade local a respeito da procissão dos caixões. Essa cena, quase estática do ponto de vista das câmeras, é bastante longa e é preciso atenção ao conteúdo da conversa. O padre, bem mais novo em idade e em tempo de residência no local, quer proibir a realização da procissão de caixões com o argumento principal de que uma mãe, entendida aqui como a Santa, não gostaria de ver um filho deitado em um leito de morte, muito menos passando pelas pessoas no meio da rua. A senhora, de forma bastante enérgica e enfática diz que a encenação é uma tradição do local e que as pessoas não irão abandonar aquilo. O padre então continua a reforçar seu argumento de que aquilo não condiz com a real fé católica e que as pessoas deveriam procurar outro jeito de manifestar sua gratidão às graças alcançadas com a ajuda da Santa.

Desse embate resulta que as pessoas, contrariando o padre, decidem continuar com os preparativos da festa e com a procissão. A diretora do documentário em meio ao clima criado entre "comunidade versus padre", coleta o depoimento de várias pessoas: senhores, senhoras, o padre, pessoas de meia idade e jovens. Sobre os jovens, a curiosidade é que possuem uma banda de rock que irá se apresentar durante a festa religiosa a convite do padre. O contraste é evidenciado entre a tradição existente no vilarejo e a "modernidade" ou "nova realidade" a qual o novo padre está tentando passar. Esses contrastes estão presentes tanto no discurso de que a procissão não faz sentido, como na reação das pessoas que rebatem as afirmações do 
padre enfatizando a importância da tradição da festa religiosa com todo seu conteúdo, reação essa que tempos atrás seria impossível de se pensar por parte da população.

Por fim, a polêmica procissão acaba se realizando junto com a festa. No dia, há uma discussão entre as pessoas e o pároco, que nada pode fazer quando todos decidem seguir com o que já estava planejado. Também são mostradas imagens da festa onde casais de idosos dançam calmamente ao som da banda de rock dos jovens anteriormente entrevistados. $\mathrm{O}$ filme se encerra com imagens da festa e das pessoas carregando o monumento gigante que fora construído para o evento, em uma tomada de longe, mostrando a estrutura se movimentando no vilarejo.

\section{Tradição versus Modernidade}

A questão da tradição e da modernidade é algo muito presente na realidade portuguesa. Ao olharmos para o país, podemos notar como essa questão é presente naquela sociedade. Podemos tomar como exemplo a capital Lisboa, onde há uma parte nova e moderna que foi recentemente construída em meio a tradicional estrutura e arquitetura da cidade. Surgiu dai, juntamente com o documentário descrito anteriormente, a intenção em analisar esse contraste entre modernidade e tradição em Portugal.

Também convém observar que em Portugal as raízes católicas são muito fortes e a contestação por parte das pessoas em relação às ordens do padre pode ser vista como algo que afronta a própria tradição local, criando-se assim um paradoxo entre o pensamento religioso tradicional e as quebras nos padrões de comportamento quando referente à coesão e preservação da cultura e tradição de um grupo. Ainda, segundo Durkheim (1985), o contraste entre o sagrado e o profano é o traço que distingue o pensamento religioso. Seres, lugares, objetos e forças sobrenaturais são sagrados, em face ao significado que têm para o crente. Para Eliade (2008) as proscrições e tabus cercam o sagrado, e a violação das regras é considerada profanação. Todo lugar, ser, coisa ou ato que não é sagrado é profano, secular. Profano é tudo aquilo considerado útil, prático ou familiar, que pertence ao mundo cotidiano, sem possuir o significado emocional característico do sagrado: 
da árvore como árvore. A pedra sagrada, a árvores sagrada não são adoradas como pedra ou árvore, mas justamente por que "revelam" algo que já não é nem pedra, nem árvore, mas o sagrado" (ELIADE, 2008, pág. 18).

Ranquetat Junior (2009) observa que na modernidade ocidental ocorre uma espécie de sacralização do profano e do secular, onde ocorre o sincretismo, o ecletismo, a mistura de temas e práticas sendo essa uma característica da religiosidade pós-tradicional. Onde, então, residiria a tradição? E a modernidade? Se os ideais cristãos no documentário analisado estão indo contra uma parte de sua própria tradição, qual o lugar de ambas nesse contraste? Haveria então uma modernização no pensamento cristão atual que romperia com a tradição ou partes dessa?

Nesse sentido, observamos a constatação de Rodrigues (1990, p. 1) de que modernidade implica em ruptura, sendo ela mesma um produto desse rompimento:

\footnotetext{
Considerar a oposição entre tradição e modernidade é uma herança moderna, uma vez que é em relação ao processo de ruptura inaugurado pela modernidade que os ideais em relação aos quais ela se demarca são definidos como tradicionais, tal como é no que concerne aos ideais da tradição que os projetos de ruptura em relação a esses ideais são definidos como modernos.
}

Assim, segundo Santos (1995) a modernidade em si, possui uma natureza ambivalente dentro de sua própria lógica, pois ela se define como um ideal de ruptura e, para que isso aconteça, precisamos de algo a ser rompido e isso se dá no modelo que pretendemos romper. Não poderia assim, deixar de existir todo o universo tradicional e seus ideais, pois, se fossem completamente substituídos pelos da modernidade, essa perderia seu sentido por completo, uma vez que ela se define como ruptura para com os ideais tradicionais. Ou seja, sem o tradicional não haveria ruptura e assim não existiria a formação dessa modernidade e de seus atributos.

Dessa forma, quando falamos nessa herança moderna ao mesmo tempo falamos no destino tradicional que a modernidade possui, portanto, temos que reconhecer a impossibilidade da sua consumação absoluta. É por este motivo que a modernidade tem como destino a sua própria neutralização, ao cabo de um processo em que os modelos modernos da experiência não podem deixar de se tornar, por sua vez, também tradicionais. Exemplo disso é que quando algo está estabelecido, logo surge um movimento de ruptura, para quebrar esse 
paradigma e estabelecer novos padrões (RODRIGUES, 1990).

Sendo assim, podemos constatar que a tradição e a modernidade estabelecem entre si uma relatividade reciproca: moderno seria o que se define em relação àquilo que continua como tradicional tal como tradicional é tudo o que se define em relação àquilo que se exibe como moderno. Temos então, no caso do filme Senhora Aparecida, uma afirmação desse fato, pois, ao mesmo tempo em que há uma força pressionando para o rompimento de uma tradição, essa mesma força se coloca como fonte de uma nova tradição, de um novo padrão a ser adotado pelas pessoas. Dessa forma, o ideal moderno, que partiria de um setor tradicional, visaria uma substituição de ideias e valores dentro de uma comunidade, rompendo com uma tradição, mas simultaneamente lançando outra. 


\section{Referências Bibliográficas}

DURKHEIM, Émile. As formas elementares da vida religiosa. Martins Fontes. São Paulo: 1985.

ELIADE, Mircea. O Sagrado e o Profano: A essência das religiões. Pág. 16 a 23. São Paulo: Martins Fontes, 2008.

MACDOUGALL, David. De quem é essa história? in Cadernos de Antropologia e Imagem. Pág. 93 a 106; V.5, N.2. Rio de Janeiro: UERJ, 1997.

RANQUETAT JUNIOR, Cesar Alberto. Reflexões antropológicas sobre a religião na modernidade: declínio ou reconfiguração do religioso? Revista INTERAÇÕES - Cultura e Comunidade / v. 4 n.5 / p. 99-110 / 2009. Disponível em

〈http://periodicos.pucminas.br/index.php/interacoes/article/view/6689>

RODRIGUES, Adriano Duarte. Tradição e Modernidade. Universidade Nova de Lisboa. Lisboa: 1990. Disponível em <http://www.bocc.ubi.pt/pag/texto.php?html2=rodriguesadriano-tradicao-modernidade.html>

SALLES, João Moreira. "A dificuldade do documentário”. in Martins, Ecjer \& Caiuby Novais (org.) O Imaginário e o Poético nas Ciências Sociais. Bauru: EDUSC, 2005.

SANTOS, Boaventura Sousa. O social e o político na transição pós-moderna. Pág. 75 a 155. São Paulo: Cortez, 1995.

VANOYE, GOLIOT-LÉTÉ. Ensaio sobre a análise fílmica. $6^{\circ}$ Edição. São Paulo: Papirus Editora, 1994.

\section{Referência Fílmica:}

SENHORA APARECIDA. Direção: Catarina Alves Costa. Portugal, 1994. Betacam. 55 min. Produção SP Filmes. 